\title{
MOLECULAR CYTOGENETIC CHARACTERIZATION OF AN inv(Y)(p11.2q11.221 q11.222) IN A SYRIAN FAMILY
}

\author{
Al-Achkar $\mathrm{W}^{1, *}$, Wafa $\mathrm{A}^{1}$, Al-Ablog $\mathrm{A}^{1}$, Moassass $\mathrm{F}^{1}$, Liehr $\mathrm{T}^{2}$
}

\begin{abstract}
*Corresponding Author: Professor Walid Al-Aachkar, Department of Molecular Biology and Biotechnology, Division of Human Genetics, Atomic Energy Commission of Syria, P.O. Box 6091, Damascus, Syria; Tel.: +96311-213-2580; Fax: +963-11-611-2289; E-mail: ascientific@aec.org.sy
\end{abstract}

\section{ABSTRACT}

Constitutional chromosomal abnormalities are an important cause of miscarriage, infertility, congenital anomalies and mental retardation in humans. Pericentric inversions of the human Y-chromosome $[\operatorname{inv}(\mathrm{Y})]$ are rather common and show an estimated incidence of 0.6-1:1,000 in males in the general population. Most of the reported cases with $\operatorname{inv}(\mathrm{Y})$ are familial. For carriers of pericentric inversions the risk of mental retardation or multiple abortions is not apparently increased and there is no relation with abnormal phenotypic features. Polymerase chain reaction (PCR) analysis to detect microdeletions along the Y-chromosome as well as cytogenetic and fluorescence in situ hybridization (FISH) analysis were done to delineate the characteristics of an $\operatorname{inv}(\mathrm{Y})$ in a Syrian family. Thus, we present a detailed molecularcytogenetic characterization of a father and his two sons having an inv $(\mathrm{Y})(\mathrm{p} 11.2 \mathrm{q} 11.221 \sim \mathrm{q} 11.222)$ with varying mental retardation features but otherwise normal phenotype.

Keywords: Y-Chromosome; Inversion; Mental retardation; Fluorescence in situ hybridization (FISH); Ampli-conic fertility genes.

\footnotetext{
${ }^{1}$ Department of Molecular Biology and Biotechnology, Division of Human Genetics, Atomic Energy Commission of Syria, Damascus, Syria

${ }^{2}$ Jena University Hospital, Friedrich Schiller University, Institute of Human Genetics, Jena, Germany
}

\section{INTRODUCTION}

Pericentric inversions of the human Y-chromosome $[\operatorname{inv}(\mathrm{Y})]$ are rather common and show an estimated incidence of $0.6-1: 1,000$ in males in the general population [1]. Most of the reported cases with inv(Y) are familial [2] and may include progeny with aneuploidies, preferentially $+21, \mathrm{XXY}$ and other chromosomal syndromes. For the carriers of inv(Y) the risk of mental retardation, multiple abortions or phenotypic abnormalities is not apparently increased [3,4].

It makes sense that inv(Y) neither impedes the production of normal sperm nor does it predispose non disjunction of other chromosomes in the progeny [5-6], i.e., it is normally considered as a chromosomal heteromorphism [3-4]. However, inv(Y) has also been reported in association with infertility [7] and in patients with either concomitant minute Yq11 deletions [8] or a breakpoint in the 'deleted in azoospermia' (DAZ) gene cluster region [9]. In this report, we present a detailed molecular and molecular cytogenetic characterization of a family having an $\operatorname{inv}(\mathrm{Y})(\mathrm{p} 11.2 \mathrm{q} 11.221 \sim \mathrm{q} 11.222)$ over two generations and different clinical outcomes.

\section{MATERIALS AND METHODS}

Patient History. A 37-year-old male, his unrelated 32-year-old wife and the two sons of the family are reported, aged 15 and 17, respectively. The mother was healthy and had a karyotype 46,XX. Father and 
both sons had varying features of mental retardation but otherwise normal phenotypes. The parents did not have any history of miscarriages.

Cytogenetic and Molecular Cytogenetic Analyses. Cytogenetic analysis using GTG-banding was performed according to standard procedures [10]. A minimum of 20 metaphases analyzed from stimulated peripheral blood cultures were analyzed. Karyotypes were described according to the International System for Human Cytogenetic Nomenclature [11].

Fluorescence in situ hybridization (FISH) was carried out on the metaphases using commercially available probes (LSI SRY), subtelomeric for Xp/Yp and $\mathrm{Xq} / \mathrm{Yq}$ and centromeric for Y (DYZ3) (Abbott Molecular/Vysis, Des Plaines, IL, USA). Additionally centromere-near probes of the previously reported subcentromeric multicolor-FISH (subcenM-FISH) mix were applied [8]. A minimum of 20 metaphases spreads were analyzed. The results were evaluated on a fluorescence microscope (AxioImager.Z1 mot; Zeiss, Jena, Germany) equipped with appropriate filter sets to discriminate between a maximum of five fluorochromes and the counterstain DAPI (4',6-diamino-2-phenylindole). Image capturing and processing were carried out using an Isis imaging system (MetaSystems, Altlussheim, Germany).

Molecular Analysis. The azoospermia factor (AZF) microdeletions on the Y-chromosome were detected according to the procedure of Al-Achkar et al. [12].

\section{RESULTS}

Cytogenetic, Molecular Cytogenetic and Molecular Analyses. The karyotype determined by GTGbanding was 46,X,der(Y) (Figure 1). Fluorescent in situ hybridization using commercial Y-chromosomespecific probes revealed that sex determining region (SRY), AZF, Yq-heterochromatin and subtelomeric probes were in the expected positions (data not shown). Only the subcenM-FISH mix results showed the presence of a pericentric inversion (Figure 2) characterized as 46, $\mathrm{X}, \operatorname{inv}(\mathrm{Y})(\mathrm{p} 11.2 \mathrm{q} 11.221 \sim \mathrm{q} 11.222)(20 /$ metaphases). On the molecular level, the breaks appeared between the centromere and RP11-115H13, i.e., positions $6,919,727$ and $11,300,000$ as well as slightly distal from RP11-71M14, i.e., from position $15,173,599$. Thus, the main cluster of RNAbinding motif Y-chromosome (RBMY) in Yq11.223

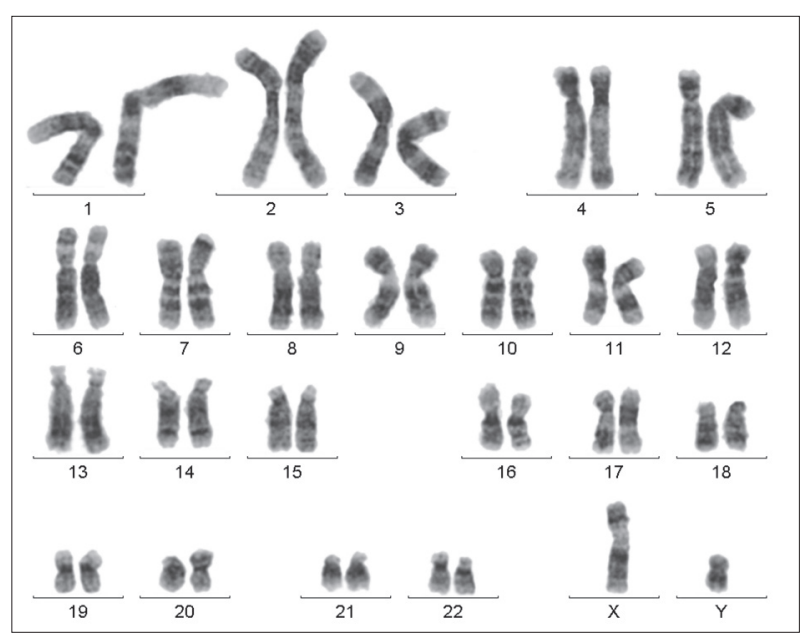

Figure 1. Karyotype from a peripheral blood meta-phase of the one of the three patients showing $46, \mathrm{X}, \operatorname{der}(\mathrm{Y})$.
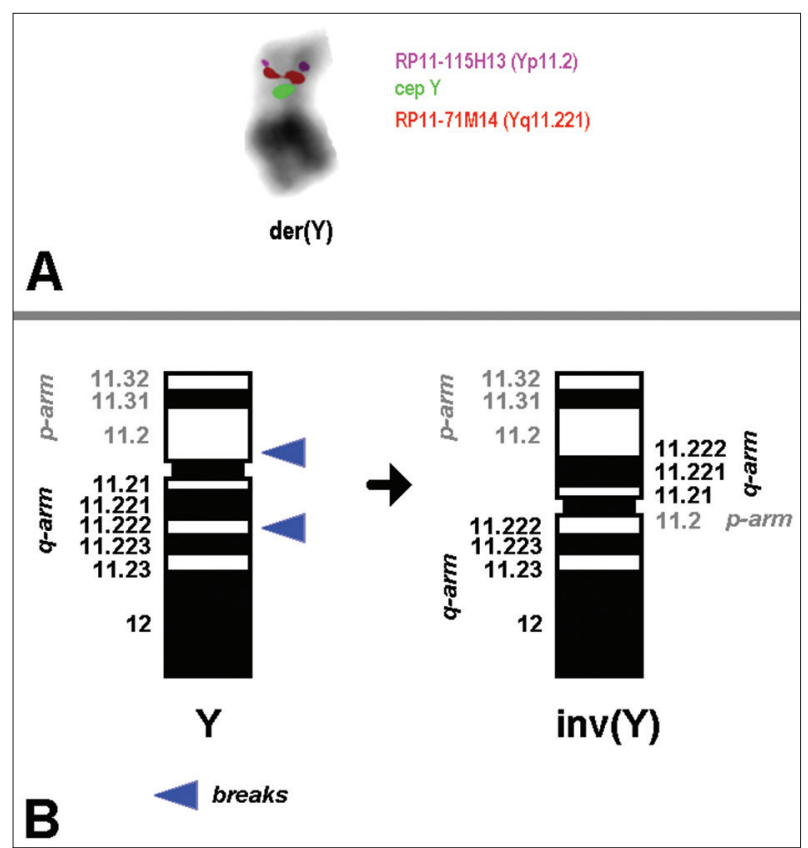

Figure 2. Centromeric probe for the Y-chromosome and centromere-near probes derived from Yq and Yp revealed the breakpoints of the pericentric inversion as Yp11.2 and Yq11.221 q11.222; the FISH results are depicted in A. $\mathrm{B}$ Schematic drawings of a normal and the derivative $\mathrm{Y}$ chromosome are shown.

to Yq11.222 and the proximal deleted azoospermia) $C D Y$ (gene in Yq11.221. Molecular genetic analysis for 26 sequence-tagged sites) STSs (Y-chromosome specific excluded AZF microdeletions in the family (data not shown). 


\section{DISCUSSION}

Constitutional chromosomal abnormalities are an important cause of miscarriage, infertility, congenital anomalies, and mental retardation in humans. The frequency of structural chromosomal abnormalities has been estimated as $0.25 \%$ in live-born infants [13]. Chromosomal polymorphisms of the constitutive heterochromatin regions of chromosomes 1, 9, 16 , and the Y-chromosome have been reported [14].

Mental retardation results from a defect in the structure and function of the neuronal synapse. Its worldwide incidence [intelligence quotient (IQ $<70$ )] is $\sim 2.0-3.0 \%$. Males are found to be more affected than females. The risk of mental retardation is higher in children with congenital structural defects [15]. The cause of mental retardation may be genetic $(30.0 \%)$ or environmental, congenital or acquired. Chromosomal aberrations account for $15.0 \%$ of mentally retarded individuals. Several types of structural aberrations are also known to cause mental retardation, the common ones being deletions, duplications, inversions, translocations and/or isochromosome formation [15].

Isodicentric $\mathrm{Y}$ chromosomes [idic(Y)] are formed by homologous crossovers between opposing arms of palindromes on sister chromatids. The authors propose that intrapalindrome sequence identity is maintained via non crossover pathways of homologous recombination. DNA double-strand breaks that initiate these pathways can be alternatively resolved by crossovers between sister chromatids to form $\operatorname{idic}(\mathrm{Y})$ chromosomes, with clinical consequences ranging from spermatogenic failure to sex reversal and Turner syndrome [6].

In all inv(Y) chromosomes cases previously described, which appear metacentric after banding analysis, the inversion breakpoints on the short arm in Yp11.2 fall in a gene-poor region of X-transposed sequences proximal to the pseudo autosomal regions (PARl) on the $\mathrm{X}$ - and Y-chromosomes at the end of the short (p) arm SRY [16,17]. However, in our familial cases, the long arm inversion breakpoint maps proximal to the fertility genes $C D Y$ and $D A Z$ in Yq11.223, resulting in our familial inv(Y)-type II. A similar familial inv(Y) case has been published [17].

In conclusion, we present a detailed molecularcyto-genetic characterization of a family who had an inv(Y)p11. 2q11.221 q11.222 with mental retardation features but an otherwise normal phenotype.
However, molecular analysis of some genes implicated in mental retardation and detection of small gains or losses of genetic material using appropriate new high-resolution test methods and/or genome sequencing should be considered for future studies.

\section{ACKNOWLEDGMENTS}

We thank Professor I. Othman, General Director of Atomic Energy Commission of Syria (AECS) and Dr N. Mirali, Head of the Department Molecular Biology and Biotechnology, Damascus, Syria, for their support. This study was financially supported by the Syrian Atomic Energy Commission, Damascus, Syria, and the Else Kroner-Fresenius-Stiftung, Jena, Germany.

Declaration of Interest: The authors report no conflicts of interest. The authors alone are responsible for the content and writing of this article.

\section{REFERENCES}

1. Bernstein R, Wadee A, Rosendorff J, Wessels A, Jenkins T. Inverted Y chromosome polymorphism in the Gujerati Muslim Indian population of South Africa. Hum Genet. 1986; 74(3): 223-229.

2. Tóth A, Gaál M, László J. Familial pericentric inversion of the Y chromosome. Ann Genet. 1984; 27(1): 60-61.

3. Motos Guirao MA. Pericentric inversion of the human Y chromosome. An Esp Pediatr. 1989; 31(6): 583-587.

4. Shapiro LR, Pettersen RO, Wilmot PL, Warburton D, Benn PA, Hsu LY. Pericentric inversion of the $\mathrm{Y}$ chromosome and prenatal diagnosis. Prenat Diagn. 1984; 4(6): 463-465.

5. Schmid M. Variations of content and structure of the mammalian Y chromosome, in Sandberg AA, Ed. The Y Chromosome, Part A, Basic Characteristics of the Y Chromosome. New York: Alan R. Liss. 1985: 373-401.

6. Luo YQ, Qian YL, Lu HM, Xu CM, Jin F. Sperm-fluorescence in situ hybridization analysis in patients with pericentric inversions of $Y$ chromosome. Zhonghua Yi Xue Yi Chuan Xue Za Zhi. 2009; 26(1): 54-56. 
7. Marchina E, Imperadori L, Speziani M, Omodei U, Tombesi S, Barlati S. Chromosome abnormalities and Yq microdeletions in infertile italian couples referred for assisted reproductive technique. Sex Dev. 2007; 1(6): 347-352.

8. Liehr T, Mrasek K, Weise A, Dufke A, Rodríguez L, Martínez Guardia N, et al. Small supernumerary marker chromosomes-progress towards a genotype-phenotype correlation. Cytogenet Genome Res. 2006; 112(1-2): 23-34.

9. Tomomasa $\mathrm{H}$, Adachi $\mathrm{Y}$, Iwabuchi $\mathrm{M}$, Oshio $\mathrm{S}$, Umeda T, Iino Y, et al. Pericentric inversion of the $\mathrm{Y}$ chromosome of infertile male. Arch Androl. 2000; 45(3): 181-185.

10. Causio F, Canale D, Schonauer LM, Fischetto R, Leonetti T, Archidiacono N. Breakpoint of a $\mathrm{Y}$ chromosome pericentric inversion in the DAZ gene area. A case report. J Reprod Med. 2000; 45(7): 591-594.

11. Shaffer L, Slovak M, Cambell L, Eds. ISCN (2009): An International System for Human Cytogenetic Nomenclature. Basel: S. Karger, 2009.

12. Al-Achkar W, Wafa A, Liehr T, Klein E, Moassass F. Detailed analysis of an $\operatorname{idic}(Y)(q 11.21)$ in a mosaic karyotype. Mol Med Report. 2012; 6(2): 293-296.

13. Jacobs PA, Hassold TJ. Chromosome abnormalities: origin and etiology in abortions and livebirths. In: Vogel F, Sperling K, Eds. Human Genetics. Berlin: Springer. 1987: 233-244.

14. Hsu LY, Benn PA, Tannenbaum HL, Perlis TE, Carlson AD. Chromosomal polymorphisms of $1,9,16$, and $\mathrm{Y}$ in 4 major ethnic groups: a large prenatal study. Am J Med Genet. 1987; 26(1): 95-101.

15. Mahajan S, Kaur A, Singh JR. Cytogenetic investigations in mentally challenged individuals. Int J Hum Genet. 2011; 11(2): 93-98.

16. Skaletsky H, Kuroda-Kawaguchi T, Minx PJ, Cordum HS, Hillier L, Brown LG, et al. The male-specific region of the human Y chromosome is a mosaic of discrete sequence classes. Nature. 2003; 423(6942): 825-837.

17. Knebel S, Pasantes JJ, Thi DA, Schaller F, Schempp W. Heterogeneity of pericentric inversions of the human y chromosome. Cytogenet Genome Res. 2011; 132(4): 219-226. 